\title{
Anti-tumour necrosis factor antibody treatment does not change serum levels of cortisol binding globulin in patients with rheumatoid arthritis but it increases androstenedione relative to cortisol
}

\author{
R H Straub, P Sarzi-Puttini, F Atzeni, F Buttgereit, M Carrabba, M Cutolo
}

Background: Cortisol binding globulin (CBG) is produced by liver cells and is inhibited by proinflammatory cytokines such as interleukin (IL) 6. CBG serum levels are typically low during prolonged inflammatory processes. Thus, observed changes of cortisol during anti-tumour necrosis factor (TNF) treatment may be related to changes of CBG in rheumatoid arthritis (RA).

Objective: To investigate the course of CBG during anti-TNF treatment in RA.

Methods: 13 patients with longstanding RA, without prior prednisolone treatment, were included in this longitudinal study with subcutaneous adalimumab.

Results: Treatment with anti-TNF markedly decreased clinical markers of inflammation and serum IL6. Serum levels of cortisol, CBG, and the ratio of cortisol/CBG did not change markedly, whereas the ratio of serum CBG/IL6 increased $(p=0.004)$. In parallel, levels of adrenocorticotropic hormone decreased during the observation period. The ratio serum androstenedione/serum cortisol increased during the study $(p=0.036)$.

Conclusions: During anti-TNF treatment relatively normal levels of CBG and a normal ratio of CBG/cortisol are found. Changes of cortisol in relation to IL6 during anti-TNF treatment, seen previously, may not be related to changes of CBG.

n a chronic inflammatory disease such as rheumatoid arthritis (RA), the hypothalamic-pituitary-adrenal (HPA) axis is altered: (a) patients have low spontaneous and stimulated cortisol secretion in relation to inflammation ${ }^{1-7}$; (b) secretion of adrenocorticotropic hormone (ACTH) relative to inflammation is inadequate ${ }^{7}$; and (c) adrenal androgens decrease. $^{8-11}$ The causes of these alterations are only partly understood, but striking changes on all levels of the HPA axis seem to have a role. Cytokines such as interleukin (IL) 6 and tumour necrosis factor (TNF) are likely to play a prominent part in these alterations.

In a German RA cohort, we recently demonstrated that long term treatment with the anti-TNF agent infliximab sensitises the pituitary gland and favours adrenal androgen secretion. ${ }^{12}$ Because production of cortisol binding globulin (CBG) may be inhibited by proinflammatory cytokines such as IL6, ${ }^{13}{ }^{14}$ changes of cortisol, seen previously, may be dependent on changes of CBG serum levels. The present study in patients with RA receiving anti-TNF treatment aimed at investigating serum levels of CBG. We used a different cohort from Italy than in the earlier study ${ }^{12}$ and
Table 1 Characteristics of the 13 female patients with RA

\begin{tabular}{ll}
\hline Characteristics & Patients with RA \\
\hline Age (years) & $58.2(2.4)\{48-73\}$ \\
Disease duration (years) & $6.5(1.8)\{0.5-20\}$ \\
Baseline ESR (mm/ 1st h) & $32.6(5.5)$ \\
Baseline C reactive protein (mg/l) & $143.4(52.3)$ \\
Baseline serum IL6 (pg/ml) & $23.2(8.9)$ \\
Positive for rheumatoid factor, No (\%) & $13(100)$ \\
Positive for antinuclear antibodies, No (\%) & $0(0)$ \\
Baseline swollen joint score (points) & $9.3(0.6)$ \\
Baseline tender joint score (points) & $10.9(0.9)$ \\
Additional treatment & \\
Prednisolone, No (\%) & $0(0)$ \\
Methotrexate, No (\%) & $13(100)$ \\
Mean weekly methotrexate (mg) & $8.7(0.9)$ \\
NSAID (COX-1, COX-2), No (\%) & $12(92)$ \\
COX-2 inhibitors, No (\%) & $5(38)$ \\
Azathioprine, No (\%) & $0(0)$ \\
Leflunomide, No (\%) & $0(0)$ \\
Chloroquine/hydroxychloroquine, No (\%) & $0(0)$ \\
Ciclosporin A, No (\%) & $0(0)$ \\
Sulfasalazine, No (\%) & $0(0)$ \\
\hline Data are given as mean (SEM) \{range\} unless stated otherwise. \\
\multicolumn{2}{l}{}
\end{tabular}

used a different anti-TNF agent adalimumab (to demonstrate possible class effects of anti-TNF antibodies).

\section{PATIENTS AND METHODS}

\section{Patients and blood samples}

In this study with adalimumab (Abbot SpA, Campoverde di Aprilia, Italy), we included 13 white patients with RA (all postmenopausal women) who fulfilled the American College of Rheumatology criteria for RA. ${ }^{15}$ The patients were selected according to the inclusion criteria of the Adalimumab Research in Active RA study (ReAct). None of the patients were receiving prednisolone or had received it previously (6 months before). All patients were given additional methotrexate (stable throughout this study) but no other immunosuppressive drugs (table 1). Patients were assigned to receive single self injections of adalimumab $40 \mathrm{mg}$ subcutaneously every other week. Efficacy assessments included the American College of Rheumatology and EULAR response criteria (FA, PS-P). ${ }^{16}$ A baseline blood sample was taken $1-2$ weeks before the start of the

Abbreviations: $A C T H$, adrenocorticotropic hormone; ASD, androstenedione; CBG, cortisol binding globulin; HPA, hypothalamicpituitary-adrenal; IL, interleukin; RA, rheumatoid arthritis; TNF, tumour necrosis factor 

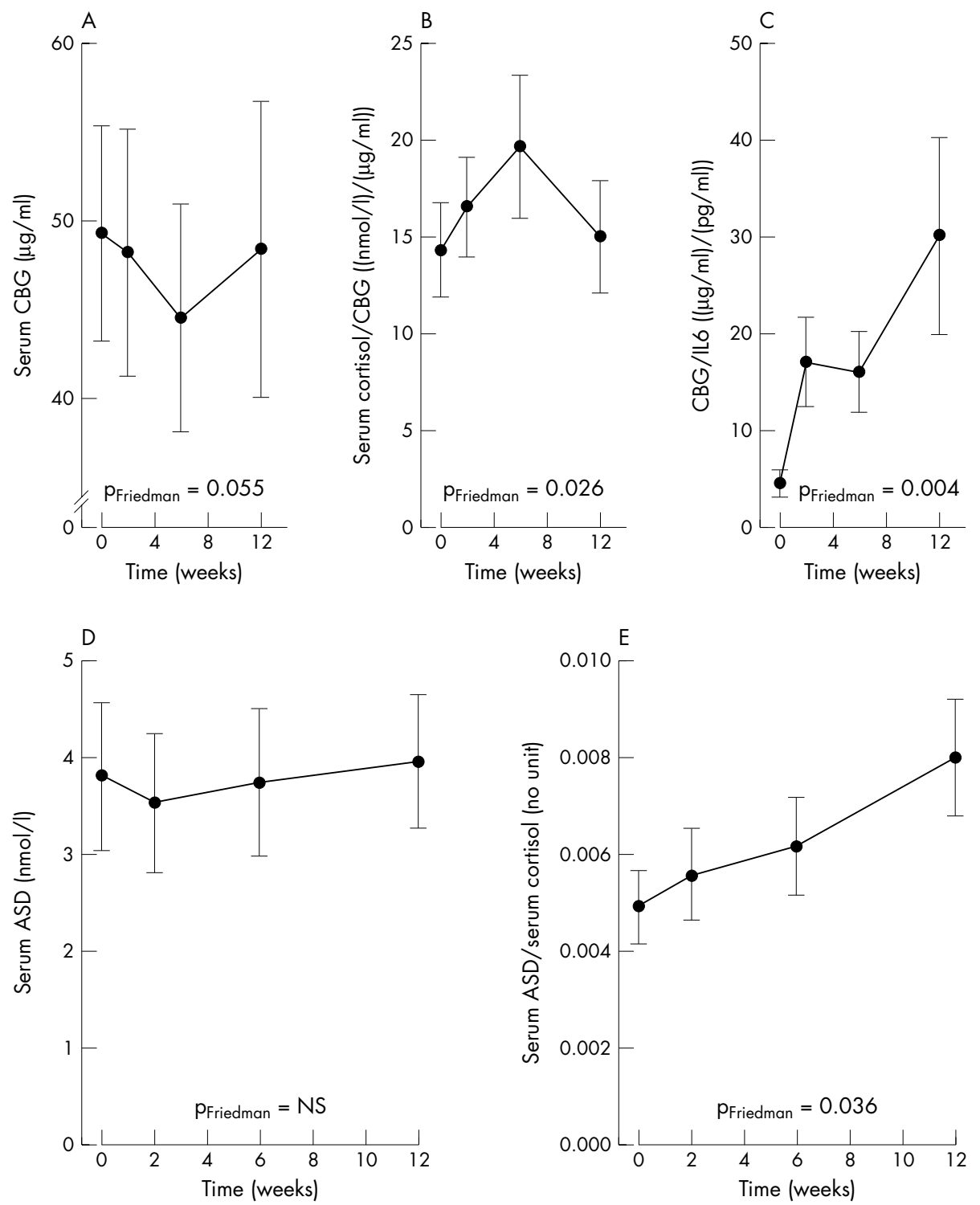

Figure 1 Course of serum cortisol binding globulin (CBG) and androstenedione (ASD) in relation to cortisol during 12 weeks of anti-TNF antibody treatment in patients with RA. Baseline values are given as time point 0 . The graph depicts serum $C B G(A)$, the ratio serum cortisol/CBG (B), the ratio serum CBG/IL6 (C), serum ASD (D), and the ratio serum ASD/cortisol (E). The data are given as means (SEM). The p value according to Friedman's test is given.

adalimumab treatment. Anti-TNF antibodies were infused on weeks $0,2,4,6,8,10$, and 12. For this study, patients were clinically investigated and blood was drawn between 800 and $900 \mathrm{am}$ when the patients visited the outpatient clinic on the baseline day or at weeks 2, 6, and 12. The blood was immediately centrifuged and serum was stored at $-80^{\circ} \mathrm{C}$. The study was approved by the ethics committee of L Sacco University Hospital, Milan, Italy.

\section{Laboratory variables}

We used radioimmunometric assays for the quantitative determination of serum levels of CBG (Biosource, Nivelles, Belgium) and cortisol (Coulter Immunotech, Marseilles, France). Serum levels of IL6 (high sensitivity Quantikine, R\&D Systems, Minneapolis, MN, USA), androstenedione (ASD; IBL, Hamburg, Germany), and ACTH (Sangui BioTech, Inc, California, USA) were measured by immunometric enzyme immunoassays. Intra-assay and interassay coefficients of variation for all tests were $<10 \%$.

\section{Statistical analysis}

Means between different time points during the course of anti-TNF treatment were compared by Wilcoxon's signed rank test for paired data (SPSS/PC, Advanced Statistics, version 11.5.1, SPSS Inc, Chicago). A decrease or increase of a variable over time (during anti-TNF treatment) was tested by the non-parametric Friedman test (SPSS). A value of $p<0.05$ was the significance level.

\section{RESULTS}

Anti-TNF treatment with adalimumab decreased the swollen joint count (baseline $v 12$ weeks: $9.3(0.6) \quad v \quad 2.9$ (0.6), $\mathrm{p}=0.001)$, tender joint count $(10.9(0.9) \quad v \quad 6.5 \quad(0.4)$, $\mathrm{p}=0.005)$, and serum levels of IL6 (23.2 (8.9) $v 3.2(1.0)$, $\mathrm{p}=0.002$ ).

Because cortisol determination may be influenced by presence of serum CBG, we measured this particular transport protein in this study. Baseline serum CBG was normal, and serum CBG did not markedly change during the 
treatment (fig 1A). Serum cortisol in relation to serum CBG also did not change during anti-TNF treatment (fig 1B). The ratio of serum CBG/IL6 significantly increased during the observation period (fig 1C).

ASD is one of the major adrenal androgens. The ratio of serum ASD/cortisol increased during the observation period, which indicates that adrenal androgen secretion increases relative to cortisol secretion (fig $1 \mathrm{E}$ ).

In addition, levels of ACTH decreased during the 12 weeks of anti-TNF treatment (baseline $v 12$ weeks: $1.6(0.1) v 1.2$ (0.1) pmol/l, $\mathrm{p}=0.007)$, but cortisol remained relatively stable $(615.3$ (81.5) v 569.6 (77.1) nmol/1). We recently demonstrated that levels of hormones in relation to serum IL6 can be used to estimate HPA axis activity in relation to this cytokine. ${ }^{7}$ This technique demonstrated that ACTH and cortisol serum levels increased relative to serum levels of IL6

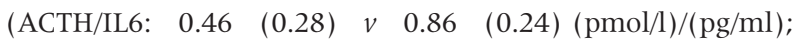
cortisol/IL6: 62.1 (22.8) v 390.2 (108.1) $(\mathrm{nmol} / \mathrm{l}) /(\mathrm{pg} / \mathrm{ml}))$. This indicates that the main hormones of the HPA axis normalise relative to serum IL6. For ACTH and cortisol, serum levels are respectively two and four times higher in relation to IL6 at 12 weeks than at baseline.

\section{DISCUSSION}

CBG binds glucocorticoid hormones and regulates their biological availability to target cells. ${ }^{17}$ CBG is mainly produced by the liver in all species examined. ${ }^{18}$ IL6 and other proinflammatory cytokines can decrease production of CBG from liver cells. ${ }^{13}{ }^{14}$ Thus, the proinflammatory load may decrease CBG serum concentrations in RA, which has been demonstrated in patients with prolonged critical illness in intensive care units. ${ }^{19}$ In this study, CBG baseline levels were normal in patients with RA. Furthermore, CBG serum levels did not markedly change during the course of anti-TNF treatment. In view of these findings, we suggest that measurement of serum levels of cortisol are not markedly influenced by CBG concentrations in patients with RA.

In addition to the marked improvement of clinical and laboratory measures of inflammation, treatment with adalimumab decreased IL6 secretion. IL6 can be considered as a hormone which informs the adrenal gland and the central nervous system about the inflammatory status of peripheral joints. ${ }^{20}$ It is important to mention that the hypothalamicpituitary axis, particularly, undergoes desensitisation upon repetitive IL6 stimuli, with a marked unresponsiveness of ACTH secretion. ${ }^{21}{ }^{22}$ Removal of the IL6 proinflammatory load by anti-TNF treatment leads to increased cortisol levels relative to IL6. This phenomenon is probably not much influenced by CBG because this transport protein remains constant. This study also demonstrated that ACTH serum levels decrease during anti-TNF treatment, which also shows that the proinflammatory load stimulates ACTH secretion. The improvement of the hypothalamic-pituitary function can further be demonstrated when serum levels of ACTH are expressed relative to IL6.

Earlier studies have shown that adrenal androgen secretion is low in patients with RA. ${ }^{8-11}$ In our earlier study we demonstrated relatively normal serum levels of ASD during the course of anti-TNF treatment. ${ }^{12}$ This was confirmed in this present study in Italian patients with RA treated with a different anti-TNF antibody. The relative preponderance of the glucocorticoid pathway (to cortisol) in relation to the androgen pathway (to ASD) was seen when the ratio of serum cortisol/ASD was used. This particular ratio increased during anti-TNF treatment with infliximab, ${ }^{12}$ which was confirmed in this present study with adalimumab. These findings suggest that anti-TNF treatment favours ASD secretion relative to cortisol.
In conclusion, our present anti-TNF study with adalimumab in an Italian RA cohort demonstrated that CBG levels are not markedly altered during anti-TNF treatment. Thus, measurement of cortisol levels during anti-TNF treatment relative to serum levels of IL6 is probably not influenced by CBG levels. Furthermore, we confirmed some of our recent findings in a German RA population using infliximab. Both studies showed that the HPA axis relative to IL6 was normalised and that adrenal androgens were increased relative to cortisol. These positive effects must be considered as an additional systemic anti-inflammatory influence of anti-TNF treatment in patients with RA.

\section{Authors' affiliations}

R H Straub, Laboratory of Neuroendocrinoimmunology, Department of Internal Medicine I, University Hospital Regensburg 93042, Germany P Sarzi-Puttini, F Atzeni, M Carrabba, Rheumatology Unit, University Hospital L Sacco, Milan, Italy

F Buttgereit, Department of Rheumatology and Clinical Immunology, Charité University Hospital, Berlin, Germany

M Cutolo, Division of Rheumatology, Department of Internal Medicine and Medical Specialties, University of Genova, Italy

Correspondence to: Professor R H Straub, rainer.straub@klinik.uni-regensburg.de

Accepted 30 January 2005

Published Online First 11 February 2005

\section{REFERENCES}

1 van den Brink HR, Blankenstein MA, Koppeschaar HP, Biilsma JW. Influence of disease activity on steroid hormone levels in peripheral blood of patients with rheumatoid arthritis. Clin Exp Rheumatol 1993;11:649-52.

2 Crofford L, Kalogeras KT, Mastorakos G, Magiakou MA, Wells J, Kanik KS, et al. Circadian relationships between interleukin (IL)- 6 and hypothalamic pituitary-adrenal axis hormones: failure of IL- 6 to cause sustained hypercortisolism in patients with early untreated rheumatoid arthritis. J Clin Endocrinol Metab 1997;82:1279-83.

3 Cutolo M, Foppiani L, Prete C, Ballarino P, Sulli A, Villaggio B, et al. Hypothalamic-pituitary-adrenocortical axis function in premenopausal women with rheumatoid arthritis not treated with glucocorticoids. J Rheumatol 1999;26:282-8.

4 Gutierrez MA, Garcia ME, Rodriguez JA, Mardonez G, Jacobelli S, Rivero S. Hypothalamic-pituitary-adrenal axis function in patients with active rheumatoid arthritis: a controlled study using insulin hypoglycemia stress test and prolactin stimulation. J Rheumatol 1999;26:277-81 .

5 Demir H, Kelestimur F, Tunc M, Kirnap M, Ozugul Y. Hypothalamo-pituitaryadrenal axis and growth hormone axis in patients with rheumatoid arthritis. Scand J Rheumatol 1999;28:41-6.

6 Kanik KS, Chrousos GP, Schumacher HR, Crane ML, Yarboro CH, Wilder RL. Adrenocorticotropin, glucocorticoid, and androgen secretion in patients with new onset synovitis/rheumatoid arthritis: relations with indices of inflammation. $J$ Clin Endocrinol Metab 2000;85:1461-6.

7 Straub RH, Paimela L, Peltomaa R, Schölmerich J, Leirisalo-Repo M. Inadequately low serum levels of steroid hormones in relation to IL- 6 and TNF in untreated patients with early rheumatoid arthritis and reactive arthritis. Arthritis Rheum 2002;46:654-62

8 Feher GK, Feher T, Zahumenszky Z. Study on the inactivation mechanism of androgens in rheumatoid arthritis: excretory rate of free and conjugated 17ketosteroids. Endokrinologie 1979;73:167-72.

9 Masi AT, Josipovic DB, Jefferson WE. Low adrenal androgenic-anabolic steroids in women with rheumatoid arthritis (RA): gas-liquid chromatographic studies of RA patients and matched normal control women indicating decreased 11-deoxy-17-ketosteroid excretion. Semin Arthritis Rheum 1984;14:1-23.

10 Cutolo M, Balleari E, Giusti M, Monachesi M, Accardo S. Sex hormone status of male patients with rheumatoid arthritis: evidence of low serum concentrations of testosterone at baseline and after human chorionic gonadotropin stimulation. Arthritis Rheum 1988;31:1314-17.

11 Sambrook PN, Eisman JA, Champion GD, Pocock NA. Sex hormone status and osteoporosis in postmenopausal women with rheumatoid arthritis. Arthritis Rheum 1988;31:973-8.

12 Straub RH, Pongratz G, Schölmerich J, Kees F, Schaible TF, Antoni C, et al. Long-term anti-tumor necrosis factor antibody therapy in rheumatoid arthritis patients sensitizes the pituitary gland and favors adrenal androgen secretion. Arthritis Rheum 2003;48:1504-12.

13 Bartalena L, Hammond GL, Farsetti A, Flink IL, Robbins J. Interleukin-6 inhibits corticosteroid-binding globulin synthesis by human hepatoblastoma-derived (Hep G2) cells. Endocrinology 1993;133:291-6. 
14 Emptoz-Bonneton A, Crave JC, LeJeune H, Brebant C, Pugeat $M$. Corticosteroid-binding globulin synthesis regulation by cytokines and glucocorticoids in human hepatoblastoma-derived (HepG2) cells. J Clin Endocrinol Metab 1997:82:3758-62.

15 Arnett FC, Edworthy SM, Bloch DA, McShane DJ, Fries JF, Cooper NS, et al. The American Rheumatism Association 1987 revised criteria for the classification of rheumatoid arthritis. Arthritis Rheum 1988;31:315-24.

16 Atenzi F, Sarzi-Puttini P, Capsoni F, Dell'Acqua D, Boccassini L, Santalena $G$, et al. Autoantibodies profile of rheumatoid arthritis patients during treatment with adalimumab. Ann Rheum Dis 2004;63(suppl I):298.

17 Hammond GL. Molecular properties of corticosteroid binding globulin and the sex-steroid binding proteins. Endocr Rev 1990;11:65-79.
18 Hammond GL, Smith CL, Underhill DA. Molecular studies of corticosteroid binding globulin structure, biosynthesis and function. J Steroid Biochem Mol Biol 1991;40:755-62.

19 Beishuizen A, Thiis LG Vermes I. Patterns of corticosteroid-binding globulin and the free cortisol index during septic shock and multitrauma. Intensive Care Med 2001;27:1584-91.

20 Chrousos GP. The hypothalamic-pituitary-adrenal axis and immune-mediated inflammation. N Engl J Med 1995;332:1351-62.

21 Mastorakos G, Chrousos GP, Weber JS. Recombinant interleukin-6 activates the hypothalamic-pituitary-adrenal axis in humans. J Clin Endocrinol Metab 1993;77:1690-4.

22 Späth-Schwalbe E, Born J, Schrezenmeier H, Bornstein SR, Stromeyer P, Drechsler $\mathrm{S}$, et al. Interleukin-6 stimulates the hypothalamus-pituitaryadrenocortical axis in man. J Clin Endocrinol Metab 1994;79:1212-14.

\section{Get published within days of acceptance with ARD}

We are delighted to announce that the Annals of the Rheumatic Diseases launched a "publish ahead of print" programme in February 2004. Selected papers are fast tracked and published online months before they appear in the print journal.

Papers of major significance to the international rheumatology community are published within days of acceptance. The first published article is the raw accepted manuscript; edited and typeset versions are also published as soon as they are available.

In addition to being available on ARD Online, the publish ahead of print articles are searchable through PubMed/ Medline-establishing primacy for your work. They are linked from the ARD Online home page.

To take advantage of this "publish ahead of print" programme submit your papers to the Annals of the Rheumatic Diseases using our online submission and review system Bench $>$ Press (http://submit-ard.bmijournals. com). For further information contact ARD@bmigroup.com. 